\title{
EXPECTATIVAS DOS CLIENTES HOSPITALIZADOS FRENTE AO RELACIONAMENTO COM A EQUIPE DE ENFERMAGEM
}

\author{
HOSPITALIZED CLIENT'S EXPECTATIONS AS TO RELATIONSHIP WITH NURSING \\ TEAM.
}

\begin{abstract}
Ana Claudia Sant'Anna Miranda' Monica Sequeira Lopes Teixeira ${ }^{1}$ Rita Batista Santos (Orientadora) ${ }^{2}$ Rosana Moraes Teles ${ }^{1}$
\end{abstract}

\begin{abstract}
RESUMO: São levantadas as expectativas dos clientes hospitalizados frente ao relacionamento com a equipe de enfermagem num setor de doenças infectoparasitárias num hospital universitário do município do Rio de Janeiro no 10 semestre de 1995. Foi elaborado um roteiro de entrevista aplicado a cinco (05) clientes, internados por mais de uma semana, de ambos os sexos e adultos. Os dados foram coletados, organizados e analisados através da construção de categorias descritivas, cuja denominação foi: a) Categoria 1: Sentimentos e Expectativas e; b) Categoria 2: Comunicação e Relacionamento. Os resultados encontrados na categoria 1 foram: 1) Carência afetiva; 2) Angústia, medo e ansiedade; 3) Solidão e depressão; 4) Reflexão; 5) Insegurança; 6) Preocupação com equipamento, de ser manipulado, cortado, tratado impessoalmente, perder o autocontrole, de dar trabalho às pessoas e dependência física. Na categoria 2 identificou-se: 1) Dúvidas e necessidade de informação acerca da sua doença, evolução do seu quadro de saúde e tempo de permanência no hospital; 2) Oportunidade de expressar sentimentos e idéias;3) Compreensão do significado da mensagem transmitida pelo enfermeiro. Enfatizou-se o fortalecimento do intercâmbio recíproco de informações, idéias, crenças, sentimentos e atitudes na interação enfermeiro-clieṇte para o desenvolvimento do relaciónamento terapêutico, com o objetivo de ajudar o cliente a satisfazer suas necessidades básicas.
\end{abstract}

UNITERMOS: Expectativas - Cliente hospitalizado - Relacionamento - Equipe de enfermagem.

\footnotetext{
${ }^{1}$ Alunas do $6^{0}$ período do Curso de Graduação em Enfermagem da Escola de Enfermagem Anna Nery da Universidade Federal do Rio de Janeiro.

2 Professora Assistente do Departamento de Enfermagem Médico-Cirúrgica da Escola de Enfermagem Anna Nery da Universidade Federal do Rio de Janeiro.
} 


\begin{abstract}
This research has been made in infectious-parasitary disease sector of a public university hospital in Rio de Janeiro on the first semester of 1995. The logbook research has been introduced to 5 adult clients, from both sexes, who had been interned in the construction of two categories, which are: a) Category I: Feelings and expectations of the client and; b) Category I: Communication and relationship between client and nurse. The results found in the first category were: 1) Lack of affection; 2) Affection, fear and anxiety; 3) Loneliness and depression; 4) Reflection; 5) Insecurity; 6) Worry about the equipment, to be cut, to be impersonally treated, lose self-control and physical dependence. The results found in the second category were: 1) Doubts and interests in information about their disease, its evolution and how long they will stay in hospital; 2) Opportunity to express feelings and ideas; 3) Comprehension of the message given by the nurse. We emphasize the increase of interchange of information, ideas, beliefs, feelings and acts in nurseclient interaction to develop the therapeutic relationship aiming at helping the client to fulfill his basic needs.
\end{abstract}

KEYWORDS: Expectations - Hospitalized client - Relationship - Nursing team.

\title{
CONSIDERAÇÕES INICIAIS
}

O interesse em desenvolver este estudo surgiu a partir da observação das reações dos clientes hospitalizados no setor de doenças infecto-parasitárias frente à assistência prestada pelas próprias autoras, durante o estágio curricular desenvolvido como parte integrante de Programa Curricular Interdepartamental do Curso de Graduação de uma Escola de Enfermagem de uma Universidade Federal Pública do Rio de Janeiro, onde os clientes mostraram-se surpresos com a comunicação terapêutica estabelecida.

A hospitalização por si só é um fator de insegurança e desencadeia reações nos clientes. A equipe de enfermagem, por estar o maior tempo em contato com o cliente, deve favorecer um bom relacionamento, conhecendo, identificando e satisfazendo as necessidades do cliente, alcançando o propósito da enfermagem através de uma assistência qualificada.

Stefanelli'3 coloca que a comunicação terapêutica contribui para a excelência da prática de enfermagem e cria oportunidade de aprendizagem para o cliente, podendo despertar sentimento de confiança entre enfermeiro e cliente, o que permitirá a ele experimentar a sensação de segurança e satisfação. Ainda diz que a comunicação tem de ser vista dentro do contexto do relacionamento onde ela ocorre, como e quando deve ser planejada para cada interação e adequada a cada situação e a cada cliente em particular. 


\section{Problema}

A partir do momento em que o individuo adoece, vê-se repentinamente obrigado a modificar seus hábitos de vida, principalmente quando é hospitalizado. Este fato só gera uma série de sentimentos e expectativas diante do novo desafio e, conseqüentemente, a insegurança emocional também está comprometida.

Quando se defrontam com os profissionais de saúde, estes sentimentos e expectativas se acentuam mais ainda devido ao medo de ser tratado impessoalmente, de ser manuseado, da dependência física, incerteza sobre a competência das pessoas que lhe darão cuidados e o sentimento de solidão.

Segundo Cordeiro et alii ${ }^{3}$, a hospitalização é um estímulo negativo para o cliente; a separação brusca dos familiares, o receio de ser rejeitado pelos seus e pelos amigos, devido a possíveis deformações, o medo de perder o emprego e outras prerrogativas, levam o cliente a apresentar condutas desajustadas, reações de insegurança, depressão ou isolamento, relacionadas ou não a tipos de enfermidade, duração ou gravidade da mesma. Assim, a equipe de enfermagem estará sempre lidando com clientes que apresentam problemas psicológicos de ajustamento, relacionados à aceitação dos limites impostos pela sua enfermidade e hospitalização, devendo procurar compreender suas atitudes, a fim de poder ajudá-los a assumir os aspectos positivos de sua personalidade.

Estes clientes podem vir a ser prejudicados a partir do momento em que a interação enfermeiro-cliente não é satisfatória e dinâmica, aumentando a insegurança emocional.

A partir dessa problemática levantada, pretende-se investigar as expectativas dos clientes hospitalizados, no setor de doenças infecto-parasitárias, frente ao seu relacionamento com a equipe de enfermagem.

\section{Justificativa do Estudo}

A partir do estudo científico realizado pretende-se minimizar as expectativas vivenciadas pelos clientes frente ao seu relacionamento com a equipe de enfermagem, visto que muitos clientes temem os profissionais do hospital, acontecendo uma submissão forçada, levando-os a não se queixarem do que. Ihes sucedem, temendo serem maltratados em represália as suas queixas e/ou por solicitarem muito o pessoal do hospital, pensam que não serão atendidos seus chamados quando estiverem em séria dificuldade e precisarem de socorro imediato.

Portanto, não é mais aceitável a colocação do cliente como mero "objeto de trabalho", algo passivo da ação de enfermagem, nem a caracterização de suas atitudes simplesmente como reações.

A relação enfermeiro-cliente deve ser um encontro real de duas pessoas, para viverem, experimentarem e estabelecerem mutuamente comunicação em uma situação 'significativa para elas, sendo desnecessário enfatizar a importância do respeito ao cliente no que toca, principalmente, à sua dignidade. 
Para Vieira ${ }^{19}$, a comunicação é importante na execução do cuidado de saúde dos indivíduos que com freqüência querem estar envolvidos nas decisões tomadas para resolução de seus problemas de saúde. Eles querem ser informados, ter suas perguntas respondidas, se isto for possivel e necessário; e querem também comunicar-se com todos os membros da equipe de saúde. Por isso, todos os profissionais devem estar preparados para responder adequadamente ao cliente, porque ele quer ser visto como uma pessoa e não como um membro, um caso ou uma coleção de sintomas.

\section{Objetivos}

\section{Objetivo Geral :}

- Avaliar as reações dos clientes hospitalizados no setor de doenças infecto-parasitárias frente ao seu relacionamento com a equipe de enfermagem.

\section{Objetivos Especificos:}

- Analisar as dificuldades de interação verbal e não-verbal relatadas pelos clientes com a equipe de enfermagem, para melhorar a assistência prestada.

- Identificar as expectativas dos clientes em relação ao seu relacionamento com a equipe de enfermagem.

\section{Definição de Termos}

Segundo Simões ${ }^{12}$ :

- Ação de Enfermagem: 1 - Unidade de produção de serviço de enfermagem envolvendo uma operação executada direta ou indiretamente para o cliente. 2 - Resultado da intervenção da equipe de enfermagem com a clientela e os demais elementos na sua assistência integral onde cada participante tem sua ação específica, podendo assim falar da ação do enfermeiro, do técnico e do auxiliar de enfermagem. 3 - Conjunto de funções que configuram o papel do enfermeiro e sua equipe.

- Assistência de Enfermagem: Consiste no conjunto de ações sistematizadas e desempenhadas pelo enfermeiro e demais elementos da equipe de enfermagem, de modo a colocar o assistido em condições de reassumir sua autonomia em questão de saúde.

- Avaliação de aprendizagem do cliente: Apreciação do contigente adquirido pelo cliente após a implementação do programa educativo de saúde.

- Efeito do cuidado de enfermagem: Resultado de uma ação de enfermagem, passivel de ser avaliada quanti-qualitivamente, com vistas à sua reconsideração.

- Expectativa: Aguardo de alguma coisa que vai acontecer; Expectação; Iminência de algum acontecimento. 
- Grau de satisfação do cliente: Aferição do quanto a assistência de enfermagem correspondeu à expectativas do cliente.

- Orientação do cliente: Explicações dadas ao cliente sobre a importância de tomar determinadas providências e de adotar certos hábitos de vida, favoráveis à sua saúde, e aceitar os tratamentos que the são propostos pela equipe de saúde.

- Relacionamento enfermeiro-cliente: Ação reciproca do processo de comunicação que se efetua entre o enfermeiro e o cliente, com a finalidade de ajudá-lo, no cuidado à sua saúde, a vencer o medo, a aumentar sua confiança na equipe e a aprender a autodeterminar-se.

- Resposta do cliente à assistência prestada: Reação do cliente aos cuidados de enfermagem recebidos.

- Sentimento: Afeto, emoção, sensibilidade, sensação, afeição, paixão, simpatia, dor, pena, pressentimento, suspeita.

- Visita de Enfermagem: Atividade realizada pelo enfermeiro ou pela visitadora sanitária na assistência aos clientes e às famílias.

\section{CONSIDERAÇÕES TEÓRICAS}

\section{Relacionamento Interpessoal Enfermeiro - Cliente}

Segundo Gattás ${ }^{4}$, embora se saiba que o relacionamento interpessoal não seja uma abordagem nova na atividade de enfermagem, ou seja, o relacionamento interpessoal sendo usado como um instrumento de trabalho, tomou conotação mais marcante a partir da década de 50 e, em decorrência disso, o incentivo ao profissional de enfermagem, no sentido de tomar conhecimento e de incluir sua própria personalidade no desempenho de suas atividades junto ao cliente.

$\mathrm{Na}$ prática de enfermagem, toda a assistência ao indivíduo se processa em nivel de relações interpessoais.

Conforme Travelbee ${ }^{4}$, a interação enfermeiro-cliente é singular, referindo esta abordagem como "da relação de pessoa a pessoa", ocorre durante um período particular na vida de ambos e, portanto, não pode ser repetida ou imitada. Uma característica dessa interação é que cada encontro é único e original, mas também representa o começo ou ponto de partida das interações subseqüentes. Todas as interações entre o enfermeiro e o cliente passam por várias fases, e muitos fatores ou variáveis determinam o desempenho de cada um através das diferentes fases. Entre eles incluem-se os conhecimentos do enfermeiro e sua capacidade para usá-los, a disponibilidade do cliente e a sua capacidade para responder à assistência e ao empenho do enfermeiro, o sexo, a idade, a religião e o tipo de problema que o cliente apresenta.

Gattás ${ }^{4}$ acrescenta ainda outras variáveis inerentes ao enfermeiro como sexo, idade, linguagem empregada, preconceitos e estereótipos em relação à 
doença do cliente, ao tipo de pessoa do cliente, seu autoconhecimento e outros. Além disso, antes que ocorra um relacionamento significativo, em que o cliente perceba ser-lhe o enfermeiro útil, de certa forma, e este sinta satisfação em desempenhar seu papel de ajuda, há um caminho a ser percorrido. Neste sobressai a importância de ambos se conhecerem como pessoas distintas, com suas próprias singularidades, assim como de desenvolverem um certo grau de confiança mútua para que possam se sentir "à vontade" na interação. E essas circunstâncias podem exigir um certo tempo para que ocorram.

De acordo com Atkinson \& Murray', a superioridade transmite ao cliente que o enfermeiro é mais inteligente, mais competente para julgar o que é melhor.

\section{“É MELHOR QUE VOCÊ FAÇA SEM PERGUNTAS O QUE EU DIGO “}

Tal atitude não encoraja o cliente a fazer perguntas, a participar no planejamento da assistência ou a tomar decisões.

Em conformidade com Vieira ${ }^{19}$, é da responsabilidade do enfermeiro explicar os cuidados administrativos, esclarecer dúvidas sobre a doença e tratamento, medicação, exame, ocorrências inesperadas no plano assistencial dentro dos limites impostos pela ética, responsabilidade profissional, potencialidade do cliente e respeitando-se sua área de trabalho na equipe de saúde profissional.

Segundo Brunner \& Suddarth ${ }^{2}$, a interação com o cliente proporciona ao enfermeiro uma oportunidade de conhecer aquilo que ele (o cliente) sabe acerca de sua doença, o tratamento, a forma de detectar e corrigir as interpretações errôneas e desinformações, identificar suas necessidades, ajudá-lo em suas dificuldades do momento, bem como realizar seu papel de ajuda.

\section{Comunicação Terapêutica}

De acordo com Cordeiro et alii $^{3}$, a comunicação com o cliente tem uma função terapêutica, além de social. É parte essencial do processo terapêutico e isto envolve escutar cuidadosamente e interpretar inteligentemente.

A função terapêutica da comunicação é estabelecida quando o cliente compartilha com o enfermeiro algum conhecimento de si mesmo que tenha significado. Isso permite ao enfermeiro conhecer seus pensamentos e sentimentos acerca da doença, de si mesmo, de um problema específico, do estresse que ele experimenta, e o enfermeiro serve de auxilio quando usa suas habilidades de ouvir, falar e perceber. O cliente se torna participante do processo em que está envolvido, passa a entender a relevância dos atendimentos que está recebendo e suas conseqüências.

Conforme Meneghin ${ }^{6}$, em seu sentido mais amplo a comunicação designa toda troca de mensagem. Considerada como processo, método ou instrumento, é por meio dela que significações são transmitidas entre pessoas ou grupos. A enfermagem fazendo uso de processos ou métodos assistenciais específicos instrumentaliza-os por meio da comunicação.

Segundo Mendes \& cols. ${ }^{5}$, por estar direta ou indiretamente interessada ou movida em favor de pessoas, a enfermagem comumente é definida como um 
processo interpessoal. Numa única interação há um fluxo e refluxo de influências no momento em que o enfermeiro e o cliente se observam e comunicam entre si pensamentos, sentimentos e atitudes. Os objetivos do enfermeiro nesta interação geralmente residem em conhecer o cliente, identificar e satisfazer as necessidades do mesmo e assim alcançar o propósito da enfermagem, qual seja: assistir o individuo, família ou comunidade na prevenção da doença e cooperar com a experiência da doença e do sofrimento e, se necessário, encontrar significado nestas experiências. Desta forma, a comunicação é um meio através do qual as metas do processo interativo podem ser alcançadas para que o propósito da enfermagem seja atingido.

Para Silva", os cuidados de enfermagem procedem de um encontro entre dois ou mais seres vivos, em que cada um detém elementos do processo de cuidados. Perceber o outro enquanto ser físico, mental, afetivo e espiritual é o segundo passo para adequar as tecnologias de manutenção da vida, da reparação e de informação às necessidades apresentadas. O primeiro passo é encontrar em si mesmo o sentido da interpretação do corpo, afeto, pensamento e espírito, para tentar aprender com e junto daqueles que vamos ter que tratar o real sentido dos cuidados que vão ser prestados.

Essa apreensão de si mesmo e do outro (indivíduo ou sociedade) é possível através da comunicação. É tarefa do enfermeiro decodificar, decifrar e perceber a significação da mensagem que o cliente nos envia para poder estabelecer um plano de cuidados adequado e coerente com as necessidades demonstradas por ele; dai a importância de se conhecer e estar atenta à comunicação verbal e não-verbal emitida por ele e por nós durante a intervenção.

Conforme Cordeiro et alii ${ }^{3}$, o processo do relacionamento terapêutico desenvolve-se durante todo $o$ tempo em que as pessoas envolvidas permanecem em interação. A interação formal é aquela que é realizada nos dias, horários e locais prédeterminados. Geralmente, é nesse momento de interação que o cliente relata seus sentimentos, pensamentos e os problemas que aumentam sua ansiedade.

De acordo com Vieira ${ }^{19}$, aproximar-se do cliente para conhecê-lo, verificar seus problemas e expectativas sentidas, observá-lo constantemente para identificação de problemas e seu atendimento são cuidados do enfermeiro, a fim de proporcionar segurança. Segurança é, por definição, o estado do que nada tem a temer.

\section{Apoio Psicológico}

Meneghin et alii ${ }^{7}$ consideram o apoio como uma das medidas mais eficazes no processo de relacionamento terapêutico. Citam Carter, que assim define apoio: a) uma pessoa percebe na outra uma necessidade não satisfeita e esta percepção pode estar ou não correta; b) há um aumento no nível de ansiedade de uma ou ambas as pessoas envolvidas na situação; c) este aumento da ansiedade é percebido por meio do sentimento empático; d) uma das pessoas faz tentativa para diminuir a ansiedade da outra; e) se a tentativa for bem 
sucedida, ambas experimentam diminuição no seu nível de ansiedade, porém, se falhar a tentativa, o nivel de ansiedade de ambas tende a aumentar, o que poderá provocar uma situação de pânico.

Hofling et aliii ${ }^{16}$ apresentam as técnicas que os enfermeiros utilizam para dar apoio: "permanecer ao lado do cliente em momentos de tensão emocional e quando demonstra perturbação e incapacidade de ver os fatos com clareza; tentar ser sensivel aos sentimentos e às necessidades do cliente; ajudar o cliente a tomar decisões e a reconhecer suas próprias limitações; planejar com o cliente suas experiências construtivas, atendendo a seus interesses sempre que possivel; ajudar o cliente a ressaltar suas características sadias, a perceber seus progressos e sucessos e a valorizá-los; oferecer ao cliente ambiente seguro para que ele teste suas habilidades sem prejuízo para si próprio e para os demais que o cercam; saber ouví-lo."

Coisak ${ }^{3}$ conclui que a orientação sistematizada no preparo psicológico do cliente submetido a qualquer tratamento terapêutico, além de promover maior grau de conhecimento do cliente em relação ao exame, promove ajuda na realização do mesmo, pois, através de sentimentos de segurança, a diminuição de expectativas torna-os mais participantes durante a realização do exame e menos susceptiveis de alterações físicas e comportamentais. Daí a necessidade do enfermeiro desempenhar funções para reduzir tensão, mediante promoção de orientações ou relacionamento positivo, que favoreçam sentimentos de segurança e cooperação.

\section{METODOLOGIA}

Trata-se de um estudo descritivo com abordagem qualitativa, já que esta é uma discussão inicial a respeito de uma realidade complexa vivenciada por acadêmicos de enfermagem, clientes hospitalizados com problemas de doença infecto-parasitárias, incluindo aspectos da totalidade de vida desses sujeitos.

Segundo Rúdio ${ }^{9}$, a pesquisa descritiva está interessada em descobrir e observar fenômenos, procurando descrevê-los, classificá-los e interpretá-los.

$\mathrm{Na}$ pesquisa qualitativa, onde os dados coletados são predominantemente descritivos, a preocupação com o processo e o significado que as pessoas dão às coisas e à sua vida são focos de atenção especial pelo pesquisador.

O grupo amostral é do tipo não probabilístico intencional, determinado por um grupo de clientes internados por mais de uma semana no setor de doenças infecto-parasitárias, de ambos os sexos e adultos, no I semestre de 1995.

O cenário para a pesquisa foi o setor de doenças infecto-parasitárias de um hospital universitário de grande porte, no município do Rio de Janeiro.

Foi elaborado um roteiro de entrevistas, que constou de Nome, Idade, Tempo de Permanência no setor, Diagnóstico Médico, e das seguintes questões: A Como você se sente quando um membro da equipe de enfermagem entra na 
enfermaria, se dirige a você, realiza um procedimento e não the diz nada ?; B Você gostaria de ser informado sobre a evolução do seu estado de saúde ?; C Durante a sua hospitalização, seus questionamentos são solucionados pela equipe de enfermagem?; D - Quais são seus sentimentos e expectativas com relação à equipe de enfermagem?; E - Você tem/sente dificuldades para se comunicar com algum membro da equipe de enfermagem ? Quais ?; F - O que você acha que poderia ser feito para minimizar ou melhorar seu relacionamento com a equipe de enfermagem ?

A coleta de dados deu-se em maio e junho de 1995, no hospital em questão. A duração da entrevista foi em torno de 20 minutos. A receptividade do grupo foi muito boa diante das perguntas, e não houve interferências nas respostas.

Após, as entrevistas foram analisadas e, a partir delas, criou-se unidades de registros - as mudanças de análise e as categorias a serem discutidas. $A$ análise e discussão foram realizadas através da construção de categorias descritivas cuja denominação foi: Categoria 1: Sentimentos e Expectativas; Categoria 2: Comunicação e Relacionamento.

A análise implicou, num primeiro momento, a organização de todo o material, dividindo-o em partes, relacionando essas partes e procurando identificar nele tendências e padrões relevantes. Num segundo momento, essas tendências e padrões foram reavaliados, buscando-se relações e interferências num nivel de abstração mais elevado.

\section{RESULTADOS: ANÁLISE E DISCUSSÃO}

Os resultados foram apresentados através das categorias previamente definidas, onde colocou-se os dados obtidos dos entrevistados e realizou-se a análise e discussão dos resultados.

\section{Sentimentos e Expectativas dos Clientes Diante da Equipe de Enfermagem}

Segundo Santos et alii ${ }^{10}$, o cliente é um individuo que geralmente possui uma carência afetiva muito grande. Por afastar-se de sua familia e ficar em contato com pessoas estranhas, pelo sofrimento imposto pelo seu estado patológico ou mesmo pelo fato de ser obrigado a estar em um hospital cujo significado possui uma conotação negativa, manifestará comportamentos variáveis resultantes da sua própria percepção e capacidade de adaptação a esse novo meio.

Ao ser admitido em um hospital, começa a existir em seu interior um sentimento de angústia caracterizado pelo medo e ansiedade. Nesta fase, começará a sentir-se sozinho e deprimido, sendo levado a refletir sobre o tipo de ambiente em que se encontra.

Também é fator de insegurança o medo de algum acidente de tratamento, a incerteza sobre a competência das pessoas que the darão cuidados, o próprio ambiente hospitalar, o medo de sentir dor, do equipamento, de ser manuseado, cortado, de ser tratado impessoalmente, de perder o autocontrole, da morte, de dar trabalho às pessoas e da dependência física. 
De acordo com Moriya \& Manzolli ${ }^{8}$, têm sido observados, com freqüência, por enfermeiros que atuam na área de doenças transmissiveis, clientes vivendo num estado de ansiedade e desassossego, com comportamentos agressivos, tentativa de suicídio, depressão, anorexia profunda, apatia, desinteresse e outras manifestações.

O primeiro passo para ativação efetiva por parte do enfermeiro, ao cuidar desses clientes, é analisar seus sentimentos em relação às manifestações de agitação, apatia e agressividade e os seus padrões habituais de comportamento em face destas.

Nas respostas dos sujeitos do estudo, os sentimentos predominantes foram de medo e ansiedade, demonstrados em conjunto ou aliados a outros sentimentos e expectativas, como fica patente nos depoimentos:

"Fico curioso em saber o porquê, mas tenho medo de perguntar e ser maltratado."

Os clientes muitas vezes deixam de serem ativos no processo de sua recuperação com medo de não serem aceitos pelos que os cercam e acabam modificando seus comportamentos e repletos de dúvidas.

Segundo Stefanelli et $a_{1 i i{ }^{16}}$, é por meio do sentimento empático que o enfermeiro transmite ao cliente a sensação de que ele é aceito.

"É bom saber se vou logo embora ou se vou ficar aqui por muito tempo."

O tempo da hospitalização é um fator de preocupação para o cliente porque gera ansiedade e angústia, o que é prejudicial, pois poderá interferir em sua segurança emocional.

"Me sinto invadido, como se fosse um vaso de plantas dentro de uma sala que alguém de vez em quando, vem e molha as plantas."

O desrespeito à privacidade, muitas vezes, deixa o cliente apreensivo, gerando um ambiente desfavorável à instalação de um clima de confiabilidade, em resposta às muitas pessoas diferentes, com funções pouco familiares, que entram em seu quarto, não prestando uma assistência de forma humanística.

Para Mendes \& cols. ${ }^{5}$, é preciso que a interação verbal do enfermeiro com o cliente fuja de um conteúdo que se limita ao comprimento de seu papel instrumental.

"Elas são ótimas, perderam seu tempo comigo quando estava nervoso."

Em conformidade com Stefanelli' ${ }^{13}$, a disposição do enfermeiro para permanecer ao lado do cliente, mesmo quando este permanece em silêncio, demonstra ao mesmo tempo que ele é aceito, independentemente do fato de falar ou não. O cliente, sentindo-se aceito, amado e valorizado como pessoa, 
tende a experimentar segurança e confiança. O cliente sente-se, então, livre de ansiedade e mais apto para expressar seus sentimentos, pensamentos e aspirar à satisfação de outras necessidades.

"Que me tratem bem, que o trabalho delas me ajude a sair daqui logo. Sei que é difícil cuidar de doentes ... para fazer o que vocês fazem tem que gostar muito."

A incerteza sobre a competência da equipe de enfermagem e a expectativa de receber alta são outros sentimentos predominantes entre os entrevistados, que pode direcionar a hospitalização a dois rumos: uma experiência traumática ou atenuação do estigma existente em relação à equipe de enfermagem, pois todo estado de tensão, angústia e carência afetiva experimentada pelo cliente pode ou não ser atenuado, e até mesmo acentuado pela equipe de enfermagem.

\section{Comunicação e Relacionamento Enfermeiro - Cliente}

Apesar de todo desenvolvimento técnico-científico, a comunicação enfermeiro-cliente deve ser o elemento chave para alcançar a excelência na assistência de enfermagem.

É por meio da comunicação que um ser humano se mantém em interação com outro, evitando a solidão. Segundo Stefanelli'it, a comunicação é uma necessidade humana básica e um processo que sustenta toda a assistência de enfermagem e o desenvolvimento do relacionamento terapêutico enfermeirocliente.

A comunicação interpessoal caracteriza-se pela presença de atos expressivos de uma ou mais pessoas, pela percepção consciente ou inconsciente destes atos por outra pessoa, e pela observação de que tais atos foram percebidos pela outra. O processo engloba meios verbais e não-verbais, onde o enfermeiro tem a habilidade de ajudar os clientes a enfrentarem tensões temporárias, a conviver com outras pessoas, a ajustar-se ao que não pode ser mudado e a enfrentar os bloqueios da auto-realização.

O processo de comunicação é essencial no relacionamento enfermeirocliente, devido às próprias dificuldades inerentes ao comportamento humano.

“Quase não pergunto nada. Antes eu perguntava, mas não entendia muito bem o que diziam, agora só pergunto se vou embora logo."

"A maioria enrola e acaba não respondendo o que quero saber; dizem que vão procurar e não trazem a resposta."

A fim de que o cliente possa sentir-se livre para falar, ele precisa sentir-se aceito como pessoa, pois esta é uma das necessidades humanas básicas. Aceitar o cliente tal como ele é não implica em aprovação de todo seu comportamento; o cliente não deve deixar de fazer seus questionamentos; caso não compreenda a explicação, deve informar ao enfermeiro para que suas dúvidas sejam esclarecidas. 
Muitas vezes os enfermeiros usam termos técnicos de difícil compreensão, fazendo com que o cliente fique sem informação. O enfermeiro deve ter conhecimento da dificuldade do cliente em aprender e compreender todas as informações dadas; para isso deve sempre enfatizar as idéias principais, avaliando sua compreensão e nunca deixar o cliente sem respostas.

“Só quero saber se estou ou não melhorando; para poder ajudar quando estou piorando e despreocupar minha família quando estou bem."

É importante a comunicação do cliente com o enfermeiro para que o cliente possa cooperar e compreender a evolução do seu quadro de saúde, e informar ao seus familiares seu estado de saúde e sua recuperação, tranqüilizando-os.

“Tem enfermeiras que respondem, tem outras que não falam nada, tem enfermeira que chega aqui faz um bando de perguntas, mas quando é nossa vez de perguntar tem que ir embora."

A comunicação enfermeiro-cliente não deve ser unidirecional, ou seja, um monólogo onde só o enfermeiro fala; deve ser dada oportunidade ao cliente para se manifestar.

Segundo Bradley \& Edinberg ${ }^{13}$, a comunicação unidirecional torna-se mais fácil para o enfermeiro, pois este detém o controle da situação. O cliente tornase um elemento passivo quando recebe orientação sobre algum exame que irá fazer, não tendo oportunidade de esclarecer suas dúvidas. O resultado, em geral, é a não cooperação do cliênte durante a realização do exame por falta de compreensão da mensagem, a qual não foi avaliada.

“Não sei, é de cada um, se não quiser falar comigo ... não fala, mas se me ouvir é melhor para mim."

Para Stefanelli et alii ${ }^{16}$, o saber ouvir, técnica de comunicação terapêutica, é um recurso eficaz que o enfermeiro pode usar para oferecer apoio ao cliente. $\mathrm{O}$ saber ouvir requer do enfermeiro esforço de concentração, disponibilidade de tempo para dedicar ao cliente e reflexão profunda para tentar entender o significado da mensagem que o cliente transmite.

\section{CONSIDERAÇÕES FINAIS}

Conclui-se que o processo de interação enfermeiro-cliente dado durante a formação profissional não são efetivados na prática devido à própria situação organizacional dos hospitais que, com maior freqüência, dirige o enfermeiro a atuar em atividades gerenciais em detrimento de todas as outras atividades para as quais houve um processo formal de ensino-aprendizagem (assistência, pesquisa etc.). Isto configura-se numa contradição, pois, segundo Taylor $^{18}$, o papel de enfermeira nas interações consiste em ser: 1) Criadora de um ambiente 
terapêutico, quando oferece oportunidade para que os clientes se sintam aceitos ali; 2) Agente Socializadora, no momento em que ajuda o indivíduo dentro dos grupos a planejarem e a participarem de eventos sociais; 3) Conselheira, sempre que os clientes precisarem de alguém que os escute com compreensão e empatia enquanto falam sobre problemas inquietantes; 4) Professora, quando leva os clientes a aprenderem como atuar de modo socialmente mais aceitável; 5) Figura parental substituta, oferecendo apoio emocional e compreensão ou cuidando com carinho; 6) Técnica, quando desempenha cuidados de enfermagem com administração de medicamentos ou tratamentos; 7) Terapêutica, encontrando-se com familias, individuos ou grupos... e engajandoos num processo que visa ajudá-los a realizar alterações fundamentais no sistema.

O processo de interação enfermeiro-cliente é fundamental para o desenvolvimento de uma assistência de enfermagem integral, contribuindo para a recuperação do cliente, já que a enfermeira provavelmente jamais ficará limitada a um único papel, num determinado momento; geralmente atuará em todos, ou em vários deles de uma só vez.

O enfermeiro deve ter consciência de que as necessidades que devem ser satisfeitas são as do cliente e não as suas; deve ser capaz de dedicar um certo tempo ao cliente, preocupar-se e demonstrar interesse por ele, sem nada exigir em troca.

\section{REFERÊNCIAS BIBLIOGRÁFICAS}

1. ATKINSON, L.D. MURRAY, M.E. - Fundamentos de Enfermagem. Rio de Janeiro: Guanabara Koogan, 1989.

2. BRUNNER, L.S. SUDDARTH, D.S. - Tratado de Enfermagem MédicoCirúrgica. Rio de Janeiro: Guanabara Koogan, 1993.

3. CORDEIRO, A.L.A.O. et alii - Apoio Psicológico ao paciente - Uma prioridade da Assistência de Enfermagem. Revista Baiana de Enfermagem, Salvador, v.2, n.1, p.119 - 135, jun. 1986.

4. GATTÁS, M.L.B. - Relacionamento Interpessoal Enfermeiro-Paciente. Revista Paulista de Enfermagem, São Paulo, v.4, n.2, p.59 - 61, abr./ jun. 1984.

5. MENDES, I.A.C - O Padrão de Comunicação do Enfermeiro com o Paciente. Revista Paulista de Enfermagem, São Paulo, v.8, n.1, p.13 - 15, jan./ fev./ mar. 1988.

6. MENEGHIN, P. - AIDS: Assistência de Enfermagem e Revisão de Literatura. Revista Paulista de Enfermagem, São Paulo, v.6, n.3, p.99 - 107, jul./ ago./ set. 1986. 
7. MENEGHIN, P.; STEFANELLI, M.C. CIANCIARULLO, T. I. - Comunicação na Enfermagem em nivel organizacional - Questões e Opções. Revista Paulista de Enfermagem, São Paulo, v.10, n.3, p.115 - 120, set./ dez. 1991.

8. MORIYA, T.M. MANZOLLI, M.C. - Isolamento em Doenças Transmissiveis: Conceituação em Enfermagem. Revista Escola de Enfermagem São Paulo, São Paulo, v.20, n.2, ago. 1986.

9. RÚDIO, F.V. - Introdução ao Projeto de Pesquisa Científica. Petrópolis: Vozes, 1986

10. SANTOS et alii - Envolvimento Emocional do Acadêmico de Enfermagem com o paciente: reflexos dessa experiência na vida futura do profissional. Revista Brasileira de Enfermagem, Brasilia, v.39, n.1, p.61 - 66, jan./ mar. 1986.

11. SILVA, M.J.P. - Percebendo os sentimentos de maneira não-verbal. Revista Paulista de Enfermagem, São Paulo, v.10, n.3, p.128 - 132, set./ dez. 1991.

12. SIMÕES, C. - Glossário de Enfermagem, Rio de Janeiro/ São Paulo: Livraria Atheneu, 1983.

13. StEFANELLI, M.C. Comunicação com o Paciente-Teoria e Ensino. Rio de Janeiro: Robe Editorial, 1993.

14. STEFANELLI, M.C. - Importância do Processo de Comunicação na Assistência de Enfermagem. Revista da Escola de Enfermagem da USP, São Paulo, v.15, n.3, p.239 - 245, dez. 1981.

15. - Jogando e Aprendendo Comunicação Enfermeira-Paciente. Revista da Escola de Enfermagem da USP, SP, v.26, n.3, p.219 - 234, ago. 1992.

16. STEFANELLI, M.C.; ARANTES, E.C. FUDUKA, I.M.K. - Aceitação, Empatia e Envolvimento Emocional no Relacionamento Enfermeiro-Paciente. Revista da Escola de Enfermagem da USP, São Paulo, v.16, n.3, p.245 - 253, dez. 1982.

17.

- Apoio como medida terapêutica no Relacionamento Enfermeiro-Paciente. Revista da Escola de Enfermagem da USP, São Paulo, v.15, n.1, p.43 - 48, abr. 1981.

18. TAYLOR, C.M. - Fundamentos de Enfermagem Psiquiátrica. Porto Alegre: Artes Médicas, 1992.

19. VIEIRA, T.T. - O Processo da Comunicação na Enfermagem. Salvador: Universidade Federal da Bahia, Centro Editorial e Didático, 1978. 